\title{
Development of Inner-Grooved Tubes by Dieless Micro-Forming with Laser-as-Sisted Air Pressure
}

\author{
Ching-Min Cheng ${ }^{1}$, Ming-Zheng Tu${ }^{1}$, Tun-Ping Teng ${ }^{2}$, Shang-Pang $\mathrm{Yu}^{1}$, Cheng-Yi $\mathrm{Yu}^{2}$ and $\mathrm{Yu}-\mathrm{Tai}_{\mathrm{C}} \mathrm{Chang}^{1}$ \\ ${ }^{1}$ Department of Mechatronic Engineering, National Taiwan Normal University, Taiwan \\ ${ }^{2}$ Department of Industrial Education, National Taiwan Normal University, Taiwan
}

\begin{abstract}
Grooved tubes are widely used in electronic cooling modules. They are usuallt drawn, a term referring to molding. However, this process has limitations, especially in the production of smaller tubes. Therefore, this study examines the potential of an alternative process, dieless forming, in which the grooves on stainless steel are generated by pulsed laser-assisted air pressure. To begin with, the stainless steel tube in ambient air was heated using a pulsed laser. Then, groove samples were sliced for observation using an optical microscope (OM). Finally, the samples were analyzed using Scanning Electronic Microscope (SEM). The results demonstrate that grooves can be formed utilizing dieless forming with pulsed laser-assisted air pressure. The average observed depth of the grooves 208.5 um at 10watt power and $0.01 \mathrm{Mpa}$ gas pressure. In conclusion, grooves at a micro scale can be produced effectively by dieless forming for a range of industrial applications.
\end{abstract}

\section{Introduction}

Moore's Law [1] holds that, all electronic devices become smaller and smaller over time. This trend extends to consumer electronics, whose requirements for tiny components are constantly increasing. Rapid development of both the software and hardware components of smartphones, for instance, implies that there will be increasing demand for advanced heatdissipation solutions. In recent years, such solutions have included micro heat pipes. [2]

The diameter of micro heat pipes can affect the efficiency of heat dissipation, because increasing surface area reduces air-flow resistance and elevates thermal conductivity. As compared to heat pipes without internal structures, the thermal conductivity of heat pipes with internal tread increases by $30 \%$ to $40 \%$. In the early stages of their development, the usual diameter of heat pipes was $9.52 \mathrm{~mm}$. this was subsequently reduced to 7 $\mathrm{mm}$, and from 1995 , to $5 \mathrm{~mm}$.

Tube forming refers to changing the shape of a tube by external force using a mold or die. Recently, there has been a marked downward shift in the size of tube forming. In seeking to obtain an ideal size of tube while maintaining the quality of the material, mold processing is of crucial concern. [3]

There are three types of heat pipes: 1) grooved, 2) screen, and 3) sintered. This paper will focus on the grooved type, which is generally produced by roll forming. The roll-forming process begins with the feeding of a flat metal sheet into a series of calendering machines in order to produce a tube with an inner spiral ribbed surface. [4] After the tube has been formed, its size will be reduced using multiple rollers rotating in a cycle around the tube while it is drawn in the axial direction. This process has the limitation that, once the tube is reduced, the geometric section of its inner groove will deform. [5], [6] The present research attempts to solve this problem by forming inner-grooved tubes via dieless forming instead of roll forming.

\section{Experimental}

This experiment was performed using a ROFIN starweld $40 \mathrm{~W}$ Nd:YAG pulse-laser welding machine with a FANUC Robot LR Mate200i six-axis robot arm. (Fig. 1) The forming process as show in Fig. 2 took place at standard atmospheric pressure without preheating or noble gas. A precision pressure regulator and air filter regulator were chosen to maintain the pressure. Because an air lubricator would have changed the accuracy of the precision pressure regulator, it was excluded from this experiment.

Prior studies have noted that the forming pressure of tubes at ambient temperature is generally beyond $10 \mathrm{Mpa}$; and at low pressure of around $1 \mathrm{Mpa}$, several attempts may be required for forming. In this study, the forming pressure was much lower due to the use of laser heating. The pressure parameters should be in keeping with the parameters of the laser if fractures are to be avoided. The main laser parameters are power, pulse width, pulse frequency, robot-arm movement speed, and overlap rate. Among all five of these parameters, power and pressure are the most important. Pulse width affects the geometric 
size of the groove, while pulse frequency and the speed of the robot arm control the overlap rate. In this research, SUS $301 \varphi 2 \mathrm{~mm} \times 0.2 \mathrm{~mm}$ stainless steel was used as a specimen. The related parameters were set as follows: power, 8-12 W; pulse width, 3-5 ms; pulse frequency, 4-5 $\mathrm{Hz}$; robot-arm movement speed, $1 \mathrm{~mm} / \mathrm{sec}$; and pressure, 0.007-0. 015 Mpa in Table 1.

The experiment results were observed using SEM and an OM.

Table 1. Experiment parameters

\begin{tabular}{|c|c|}
\hline material & SUS301 \\
\hline power $(\mathrm{W})$ & $8-12$ \\
\hline Pulse Width $(\mathrm{ms})$ & $3-5$ \\
\hline Pulse frequency $(\mathrm{Hz})$ & $4-5$ \\
\hline speed $(\mathrm{mm} / \mathrm{sec})$ & 1 \\
\hline Pressure $(\mathrm{Mpa})$ & $0.007-0.015$ \\
\hline
\end{tabular}

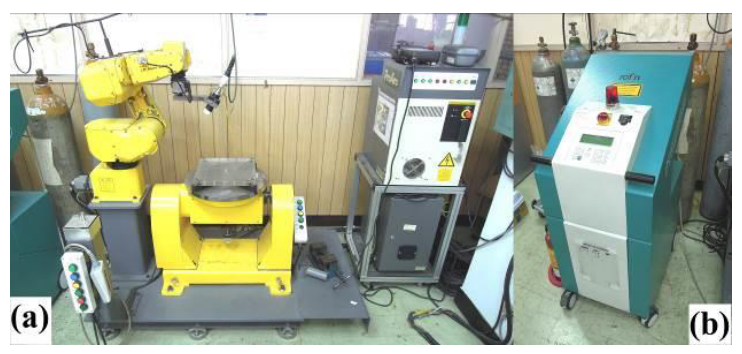

Figure 1. Experimental equipment, (a) FANUC Robot LR Mate200i six-axis robot arm (b) Nd:YAG pulse-laser welding machine.

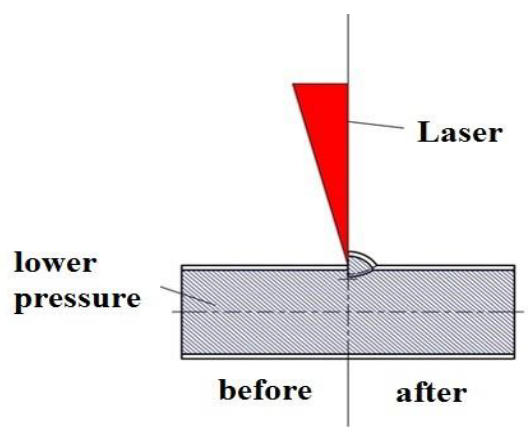

Figure 2. Approach forming

\section{Results and discussion}

The specimens were analyzed using SEM, and a significant result was found regarding atmospheric pressure. The related parameters were as follows: power $10 \mathrm{~W}$, pulse width $4 \mathrm{~ms}$, and pulse frequency $4.5 \mathrm{~Hz}$. While the specimens' surfaces were being heated by the laser, the groove was not generated, since there were no pressure differences. However, the melted inner wall was found to be lower than the surface due to effect of gravity, as shown in Fig. 3. If the forming pressure was increased to $0.007 \mathrm{MPa}$, the groove could be shaped, with a width of $79 \mathrm{um}$. There was no sharp difference in wall thickness, as shown in Fig. 4. When the forming pressure was augmented to $0.01 \mathrm{MPa}$, the groove was completed, and its average width was $208.5 \mathrm{um}$. the wall thichness was thinner than it was originally, as shown in Fig. 5. If the forming pressure was increased to $0.015 \mathrm{MPa}$, random fractures would occur, as shown in Fig. 6. The relationship between pressure and the average depth of inner grooves is presented in Fig. 7.
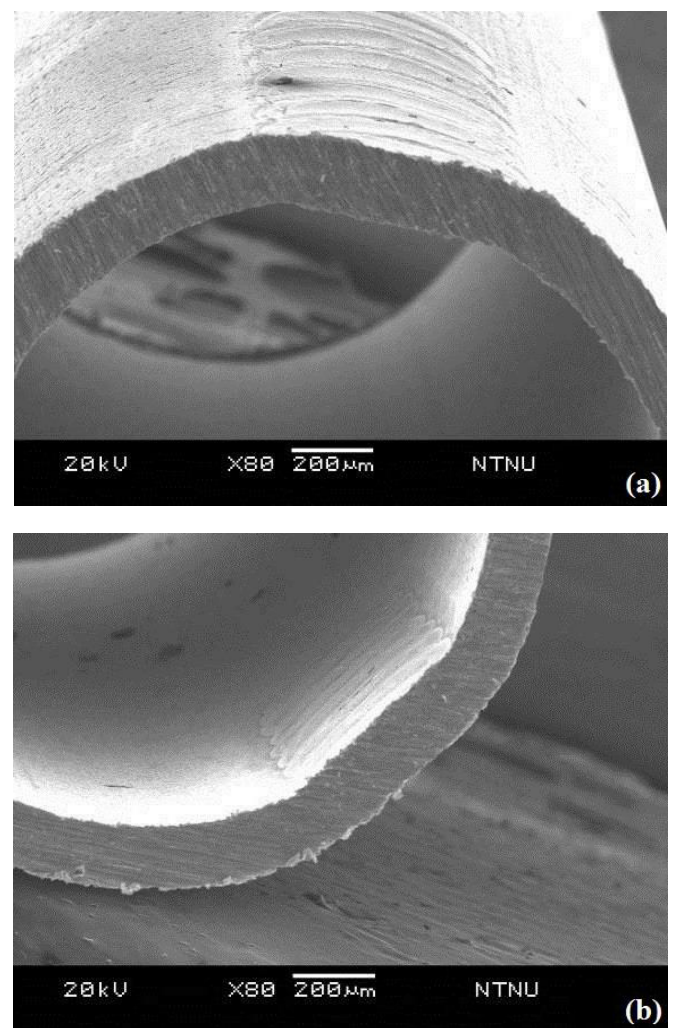

Figure 3. Inner groove was not formed since there were no pressure differences at atmospheric condition. (a) Outside of the tube (b) inside of the tube.
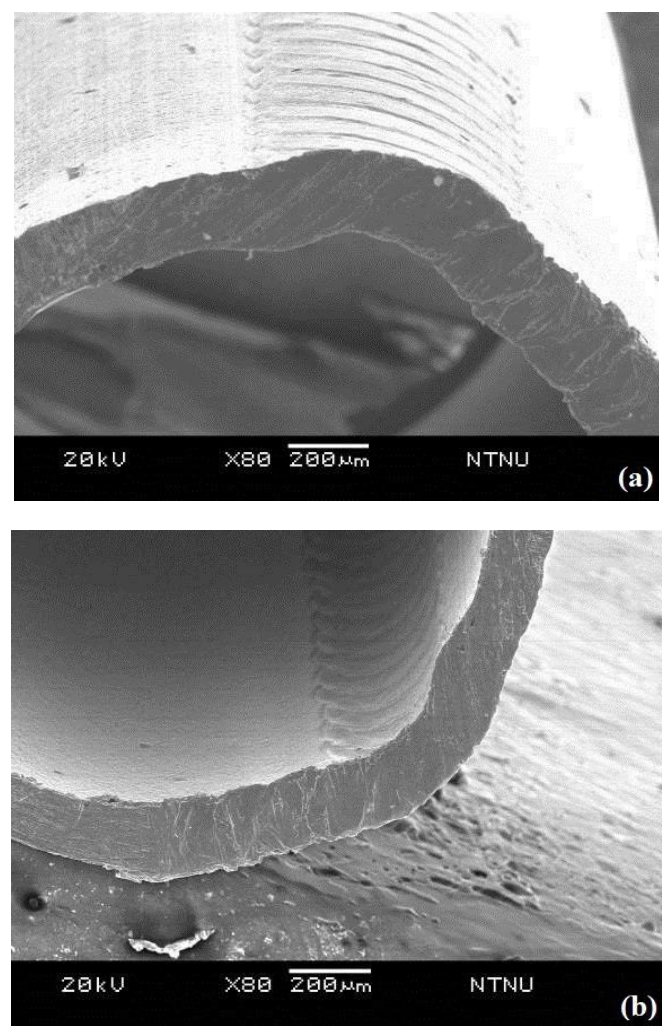

Figure 4. Inner groove formed when the pressure differences reach to $0.007 \mathrm{Mpa}$, and the average depth was $79 \mathrm{um}$. (a) Outside of the tube (b) inside of the tube. 


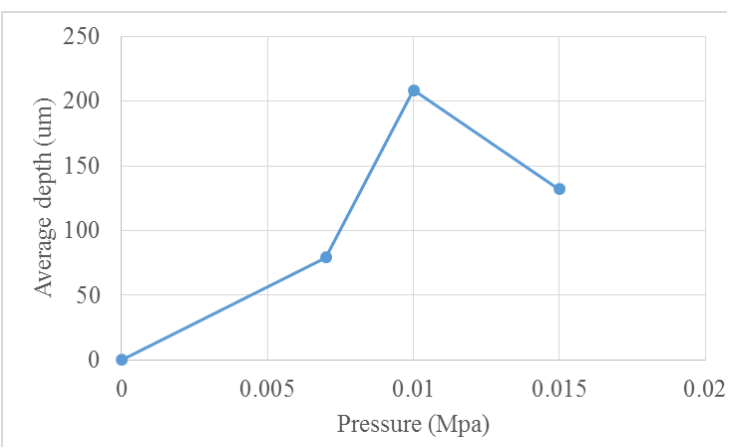

Figure 7. The relationship between pressure and average depth.

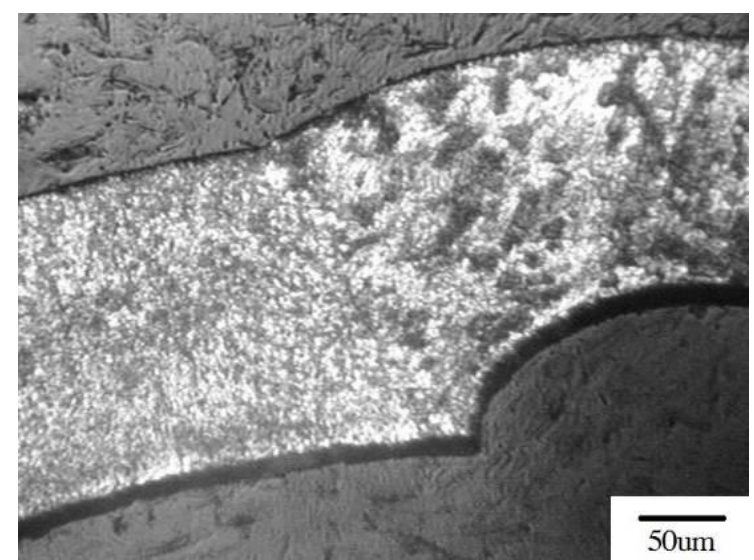

Figure 8. The melted specimen presented columnar in radial direction after being pressed.

gure 5. A completely inner groove could be formed when pressure differences reach to $0.01 \mathrm{Mpa}$, and the average depth was $208.5 \mathrm{um}$. (a) Outside of the tube (b) inside of the tube.
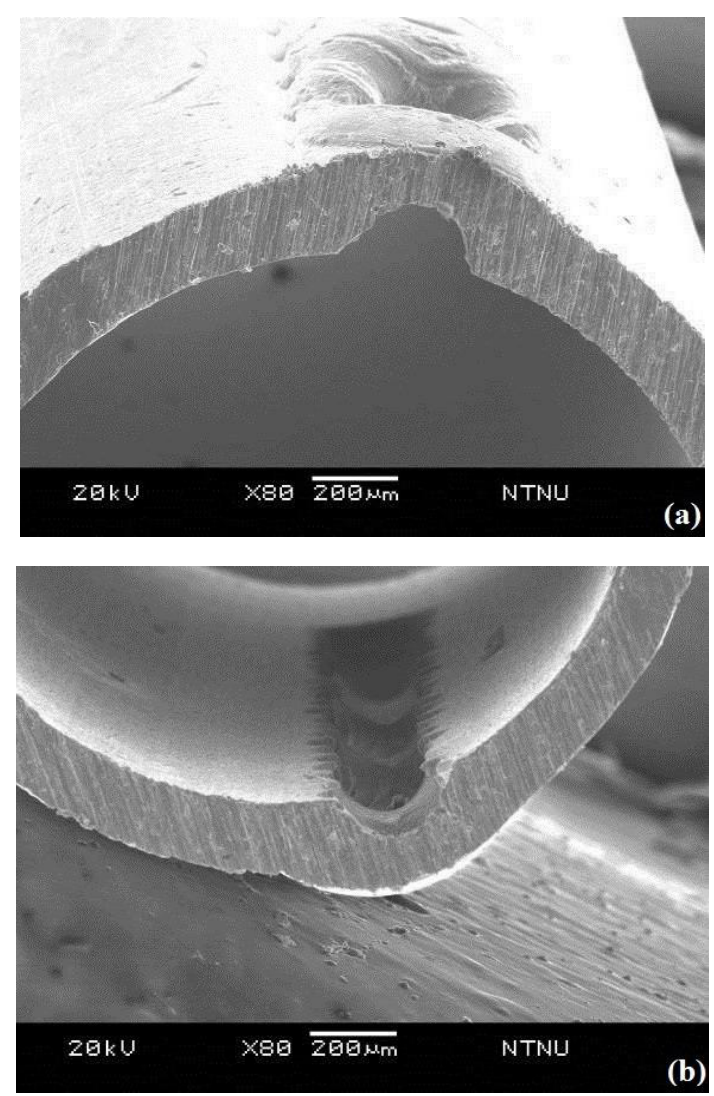

Figure 6. Random fracture would happen when the pressure differences reach to $0.015 \mathrm{Mpa}$. (a) Outside of the tube (b) inside of the tube.

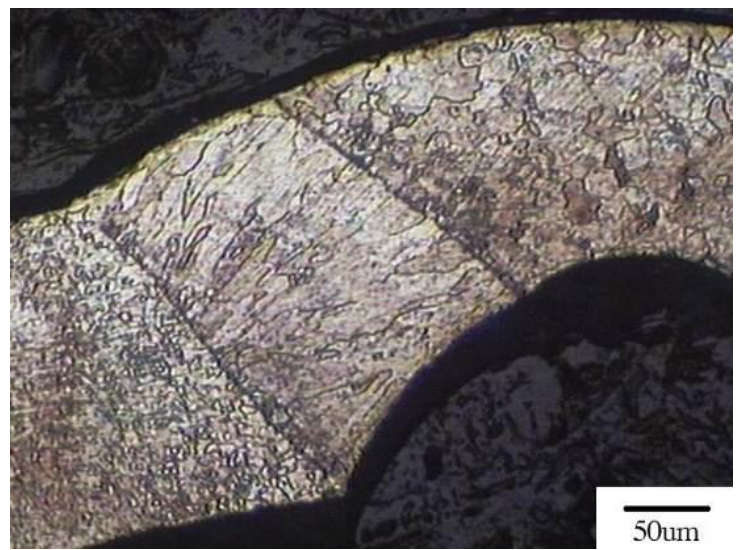

Figure 9 Different structures generated in different conditions

The metallography results imply that the setting of parameters impacts considerably on the structure of the groove. Two conditions were selected, and are depicted in Fig. 8\&9. In Fig. 8, the groove was formed due to inner pressure while the specimen was melted. The structure in the radial direction was columnar, and that in the axial direction tool the form of dots. In Fig. 9, the inner pressure also affected the forming when at duplex.

\section{Conclusion}

This research on the feasibility of creating inner-grooved tubes by dieless forming utilized. Stainless steel specimens heated by laser in standard atmospheric conditions. It was found that: 
1. Inner tube structure can be formed successfully using this dieless process.

2. The average depth of the inner grooves obtained was 208.5 um.

3. Inner tubes can be formed dielessly at lower pressure $(0.01 \mathrm{MPa})$, which is safer and less costly than hydroforming, which requires pressure of $2 \mathrm{MPa}$.

4. The diameter of the hole was controllable.

5. The forming position and length were unrestricted.

\section{References}

1. G. E. Moore, Cramming more components onto integrated circuits, Electronics, 38, p. 114, (1965).

2. H.-T. Lim, S.-H. Kim, H.-D. Im, K.-H. Oh, and S.-H. Jeong, Fabrication and evaluation of a copper flat micro heat pipe working under adverse-gravity orientation, Journal of Micromechanics and Microengineering, Vol. 18, Number 10, (2008)

3. G. Ngaile, J. Lowrie: Micro-tube hydroforming system based on floating die assembly, 60 Excellent Inventions in Metal Forming p.427-432, (2015).

4. L.-S. Lu, Y. Tang, W.-Q. Fang, J. Cheng, Pipe reduction of miniature inner grooved copper tubes through rotary swaging process, Trans. Nonferrous Met. Soc. China 23, p.377-384, (2013)

5. L. Lu, D. Yuan, Y. Tang, J. Cheng, Slave rotation analysis of miniature inner grooved copper tube through rotary swaging process, Int J Adv Manuf Technol, 61, p. 185-193, (2012)

6. T. Tangsri, S. Norasethasopon, Influences of total reduction of area on drawing stress and tube dimension in inner spiral ribbed copper tube sinking, Int J Adv Manuf Technol, 77, p. 2269-2276, (2015) 